Article

\title{
Performance Evaluation of Soil Moisture Sensors in Coarse- and Fine-Textured Michigan Agricultural Soils
}

\author{
Younsuk Dong ${ }^{1, * \mathbb{D}}$, Steve Miller ${ }^{1}$ and Lyndon Kelley ${ }^{2}$ \\ 1 Department of Biosystems and Agricultural Engineering, Michigan State University, \\ East Lansing, MI 48824, USA; mill1229@msu.edu \\ 2 Michigan State University Extension, Michigan State University, East Lansing, MI 48824, USA; \\ kelleyl@msu.edu \\ * Correspondence: dongyoun@msu.edu
}

Received: 10 November 2020; Accepted: 30 November 2020; Published: 2 December 2020

\begin{abstract}
Soil moisture content is a critical parameter in understanding the water movement in soil. A soil moisture sensor is a tool that has been widely used for many years to measure soil moisture levels for their ability to provide nondestructive continuous data from multiple depths. The calibration of the sensor is important in the accuracy of the measurement. The factory-based calibration of the soil moisture sensors is generally developed under limited laboratory conditions, which are not always appropriate for field conditions. Thus, calibration and field validation of the soil moisture sensors for specific soils are needed. The laboratory experiment was conducted to evaluate the performance of factory-based calibrated soil moisture sensors. The performance of the soil moisture sensors was evaluated using Root Mean Squared Error (RMSE), Index of Agreement (IA), and Mean Bias Error (MBE). The result shows that the performance of the factory-based calibrated CS616 and EC5 did not meet all the statistical criteria except the CS616 sensor for sand. The correction equations are developed using the laboratory experiment. The validation of correction equations was evaluated in agricultural farmlands. Overall, the correction equations for CS616 and EC5 improved the accuracy in field conditions.
\end{abstract}

Keywords: soil moisture sensor; sensor calibration; time domain reflectometry; frequency domain reflectometry; coarse-textured soil; fine-textured soil

\section{Introduction}

Soil moisture content is a critical parameter to understand the water and solute transports in soil. Soil moisture sensors have been used in agriculture for many years to improve the water management through precise irrigation scheduling [1-4] because of their practicability in providing continuous data, the fact that they can be installed at multiple depths, and the fact that they are not destructive. The common sensor technologies are Time Domain Reflectometry (TDR) and Frequency Domain Reflectometry (FDR). TDR uses the speed of an electromagnetic signal passing through a material that varies with the dielectric of the material and is the most accurate method to measure the soil moisture content [5]. Previous studies discuss that TDR provides the most accurate data but is expensive. While not economical, the results are independent of soil texture, temperature, and electrical conductivity, which are soil properties that affect some of the other methods [6]. FDR (electrical capacitance) uses an embedded oscillating circuit and sensor. The dielectric permittivity of the soil is recorded, and changes in the permittivity correlate with changes in the circuit frequency, which correlate with soil moisture content. This method requires calibration for different soil types since the recordings are soil specific, but the initial cost is lower than that of TDR [7]. 
The direct method to measure the soil moisture content is collecting soil samples using a 3-inch diameter ring and drying it in the oven at $105^{\circ} \mathrm{C}$ to calculate the mass of water lost [8]. This method allows for calculating gravimetric water content and soil bulk density. The volumetric water content can be calculated by multiplying the gravimetric water content by the soil bulk density. It has been commonly used to calibrate the soil moisture sensors under field conditions [9-12]. This soil sample collection method requires intense labor, soil disturbance, and does not measure the soil moisture content continuously. The continuous soil moisture content measurement provides useful information such as how the rainfall and irrigation infiltrate into the soil, and how the crop uses the water from what soil depths.

The factory-based calibration of these soil moisture sensors is generally developed under limited laboratory conditions, which are not always appropriate for field conditions [13]. Previous studies show that the factory-based calibrated sensors have shown overestimate or underestimate the soil moisture content, depending on the characteristics of the soil $[14,15]$. Because the calibration of the soil moisture sensor is soil specific, assessments on more soils are needed. The objectives of this study were (1) to evaluate the performance of factory-based calibrated soil moisture sensors; (2) to develop the correction equations for sand, loamy sand, and sandy clay loam; and (3) to validate the correction equations with a field experiment.

\section{Materials and Methods}

\subsection{Laboratory Experiment}

In order to evaluate the performance of factory-based calibrated soil moisture sensors, the laboratory experiment was conducted using 144 -liter size containers $(80 \times 41 \times 35 \mathrm{~cm})$. Figure 1 shows the overall view of this laboratory experiment. The duration of the laboratory experiment was 30 days. Sand, loamy sand, and sandy clay loam, typical soil types in Michigan, were tested. Soils were collected from the Michigan agricultural fields and the texture classification was analyzed by Michigan State University Soil Lab (East Lansing, MI, USA). The result of the soil classification is shown in Table 1. This laboratory research evaluated CS616 manufactured by Campbell Scientific (Logan, UT, USA) and EC5 manufactured by Metergroup (Pullman, WA, USA). CS616 represents TDR and EC5 represent FDR. The sensors were installed at $15 \mathrm{~cm}$ depth from the surface. The CS616 sensors were connected to CR1000 datalogger, manufactured by Campbell Scientific. EM60g datalogger, manufactured by Metergroup, was used to record the measurements for EC5 soil moisture sensors. The dataloggers were programmed to record the measurement every hour. The soils were air-dried before the experiment. The sensor performance was evaluated at low soil moisture levels, for drought condition. The water was applied manually to the containers by a sprayer with a $12 \mathrm{~V}$ diaphragm pump. Soil samples were collected using a $61 \mathrm{~cm}^{3}$ size soil ring for volumetric water content analysis. The samplings were performed six times during the experiment. The small size of the soil ring was used to minimize disturbing the soil. The containers were covered with a plastic liner to minimize the evaporation. The soil temperature was measured using 107 temperature probes, manufactured by Campbell Scientific, which was connected to CR1000 datalogger.

Table 1. Soil classification result for the laboratory experiment.

\begin{tabular}{cccccc}
\hline Container & Class & Bulk Density $\left(\mathbf{g} / \mathbf{c m}^{\mathbf{3}}\right)$ & Sand (\%) & Silt (\%) & Clay (\%) \\
\hline 1 & Sand & 1.71 & 89.5 & 4 & 6.5 \\
2 & Loamy Sand & 1.64 & 83.2 & 7.2 & 9.6 \\
3 & Sandy Clay Loam & 1.42 & 63.4 & 12.4 & 24.2 \\
\hline
\end{tabular}




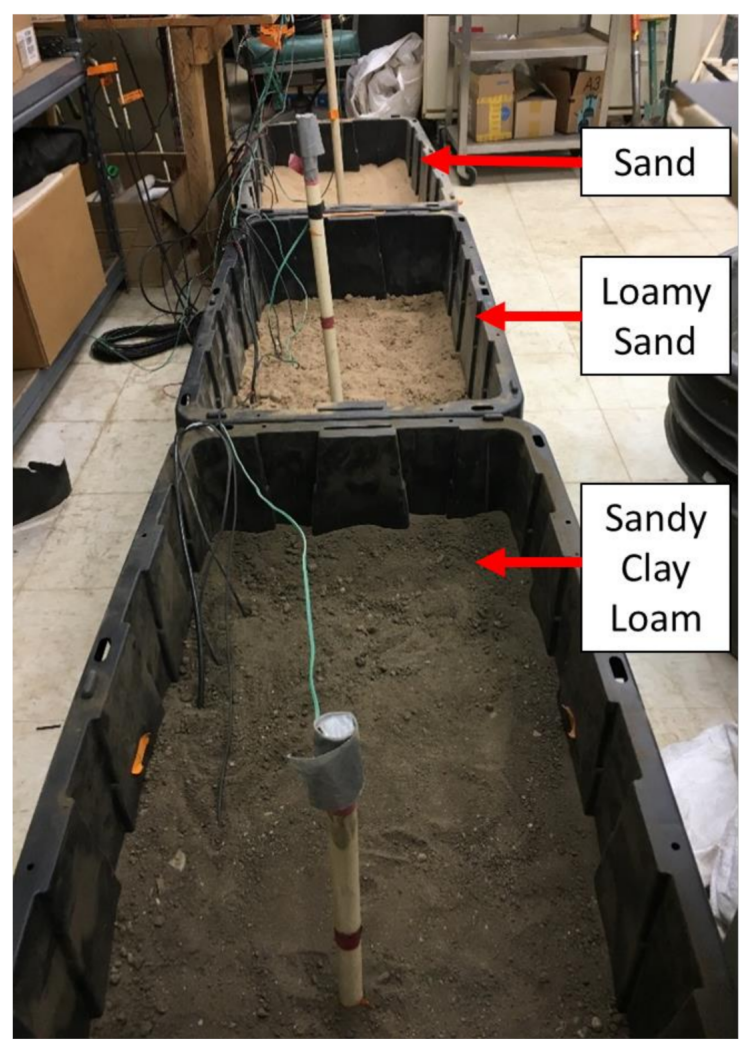

Figure 1. Overview of the laboratory experiment setup. Sand, loamy sand, and sandy clay loams, collected from Michigan agricultural fields, were used in this laboratory experiment.

\subsection{Statistical Analysis}

The performance of the soil moisture sensors was evaluated using Root Mean Squared Error (RMSE), Index of Agreement (IA), and Mean Bias Error (MBE). RMSE measures the difference between sensor values and soil sample values and is defined in Equation (1). The index of agreement was proposed by Willmott (1981), as defined in Equation (2) [16]. MBE is defined in Equation (3).

$$
\begin{gathered}
\text { RMSE }=\sqrt{\frac{1}{N} \sum_{i=1}^{N}\left(M_{i}-P_{i}\right)^{2}} \\
\mathrm{IA}=1-\frac{\sum_{i=1}^{N}\left(M_{i}-P_{i}\right)^{2}}{\sum_{i=1}^{N}\left(\left|P_{i}-\bar{M}\right|+\left|M_{i}-\bar{M}\right|\right)^{2}} \\
\mathrm{MBE}=\frac{1}{\mathrm{~N}} \sum_{i=1}^{N}\left(P_{i}-M_{i}\right)
\end{gathered}
$$

where $N$ is the sample size, $M$ is the measured (soil sampling) value, $P$ is the predicted (sensor measurement) value, $\bar{M}$ is the average measured value. The units for RMSE and MBE are volumetric water content $\left(\mathrm{cm}^{3} / \mathrm{cm}^{3}\right)$, and IA is dimensionless. A range of IA lies between 0 and 1 , and a value of 0 indicates no agreement between measured and predicted values. A value of 1 indicates a perfect fit of observed to predicted values. The higher value of IA indicates better agreement between observed and predicted values. Hignett and Evett (2008) discussed that the sensor measurement accuracy for most agricultural applications needs to be less than $0.02 \mathrm{~cm}^{3} / \mathrm{cm}^{3}$ [17]. Varble and Chavez (2011) reported that the criteria for MBE and RMSE were \pm 0.02 and less than $0.035 \mathrm{~cm}^{3} / \mathrm{cm}^{3}$ [14], respectively. Therefore, this study evaluated the sensor performance using the following criteria: $\mathrm{MBE} \pm 0.02 \mathrm{~cm}^{3} / \mathrm{cm}^{3}$ and RMSE $<0.035 \mathrm{~cm}^{3} / \mathrm{cm}^{3}$. 


\subsection{Field Experiment}

The validation of correction equations was evaluated in the agricultural fields. Four agricultural fields were selected to cover the same soil types, such as sand, loamy sand, and sandy clay loam, as the laboratory experiment. These fields were growing corn, tomato, and blueberry. The soil texture classification was analyzed by Michigan State University Soil Lab and the texture classification results are shown in Table 2. Soil samples were collected using a 3-inch diameter ring to calculate the volumetric water content. A limited number of the soil sampling were conducted to minimize disturbing the soils around the sensors. This volumetric water content data were compared to factory-based calibrated and corrected soil moisture sensor data. Sensors were installed by digging a shallow trench and inserting the sensors horizontally into the soil, then backfilling the trench. CR 1000 and EM60g dataloggers were connected to CS616 and EC5, respectively. The datalogger was programmed to collect the soil moisture levels every hour.

Table 2. Soil classification for field demonstration.

\begin{tabular}{ccccc}
\hline Sensor & Class & Sand (\%) & Silt (\%) & Clay (\%) \\
\hline \multirow{4}{*}{ CS616 } & Sand & 91.9 & 3.7 & 4.4 \\
& Loamy Sand & 87.9 & 5.8 & 6.3 \\
& Sandy Clay Loam & 54.8 & 23.6 & 21.6 \\
\multirow{2}{*}{ EC5 } & Sand & 92.3 & 1.3 & 6.4 \\
& Loamy Sand & 86.8 & 4.8 & 8.4 \\
& Sandy Clay Loam & 53.3 & 26.6 & 20.1 \\
\hline
\end{tabular}

\section{Results and Discussion}

\subsection{Performance Evaluation of Factory-Based Calibrated CS616 and EC5}

The performance evaluation of factory-based calibrated CS616 and EC5 in the sand, loamy sand, and sandy clay loam were conducted by laboratory experiments. Soil temperature during this laboratory experiment was constant at $22 \pm 1{ }^{\circ} \mathrm{C}$. Table 3 describes the result of statistical analysis. Figures 2-4 show the comparison of sensor values with measured volumetric water content by taking soil samples for sand, loamy sand, and sandy clay loam, respectively. The MBE values for the CS616 show that this sensor underestimated volumetric water content by an average of $0.01 \mathrm{~cm}^{3} / \mathrm{cm}^{3}$ in the sand, $0.03 \mathrm{~cm}^{3} / \mathrm{cm}^{3}$ in the loamy sand, and $0.02 \mathrm{~cm}^{3} / \mathrm{cm}^{3}$ in the sandy clay loam. The RMSE value for sand has met the criteria, but not loamy sand and sandy clay loam. The performance of CS616 for sand satisfied both MBE and RMSE criteria. The criteria are MBE $\pm 0.02 \mathrm{~cm}^{3} / \mathrm{cm}^{3}$ and RMSE $<0.035 \mathrm{~cm}^{3} / \mathrm{cm}^{3}$. The statistical values for the EC5 show that the sensor overestimated the volumetric water content by an average of $0.03 \mathrm{~cm}^{3} / \mathrm{cm}^{3}$ in the sand, underestimated by $0.03 \mathrm{~cm}^{3} / \mathrm{cm}^{3}$ in the loamy sand, and underestimated by $0.05 \mathrm{~cm}^{3} / \mathrm{cm}^{3}$ in the sandy clay loam. Figures 2 and 3 show that the EC 5 values were negative at the lowest moisture content, which was interesting and seemed to be a calibration issue. Except for sandy clay loam, the RMSE values for sand and loamy sand have met the criteria.

Table 3. Statistical analysis to compare measured value to sensor values.

\begin{tabular}{ccccc}
\hline Soil Type & Sensor & RMSE & IA & MBE \\
\hline Sand & CS616 & 0.010 & 0.96 & -0.01 \\
& EC5 & 0.035 & 0.82 & 0.03 \\
Loamy Sand & CS616 & 0.046 & 0.74 & -0.03 \\
& EC5 & 0.032 & 0.91 & -0.03 \\
Sandy Clay Loam & CS616 & 0.040 & 0.88 & -0.02 \\
& EC5 & 0.063 & 0.62 & -0.05 \\
\hline
\end{tabular}




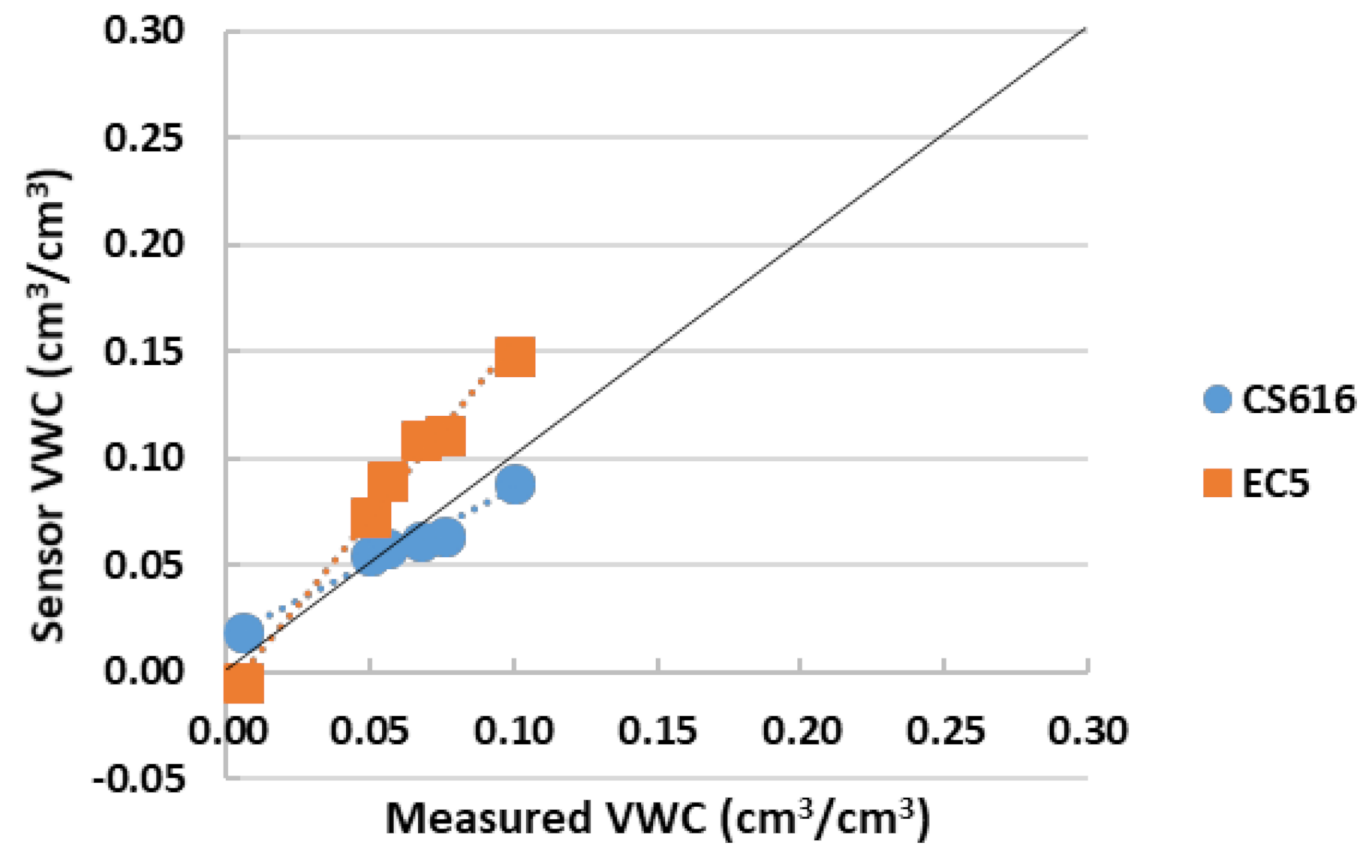

Figure 2. Comparison of CS616 and EC5 with soil sampling method for sand.

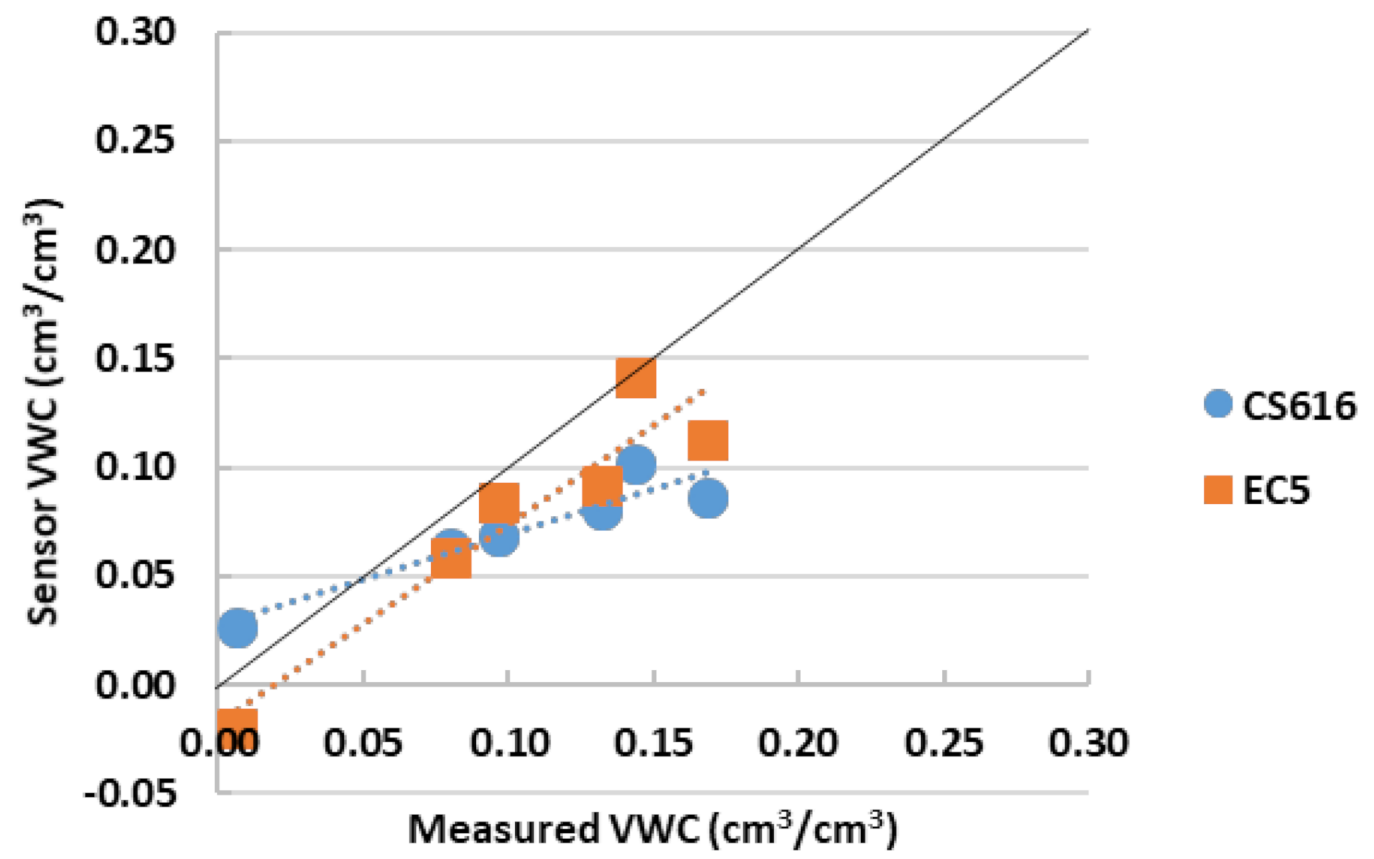

Figure 3. Comparison of CS616 and EC5 with soil sampling method for loamy sand. 


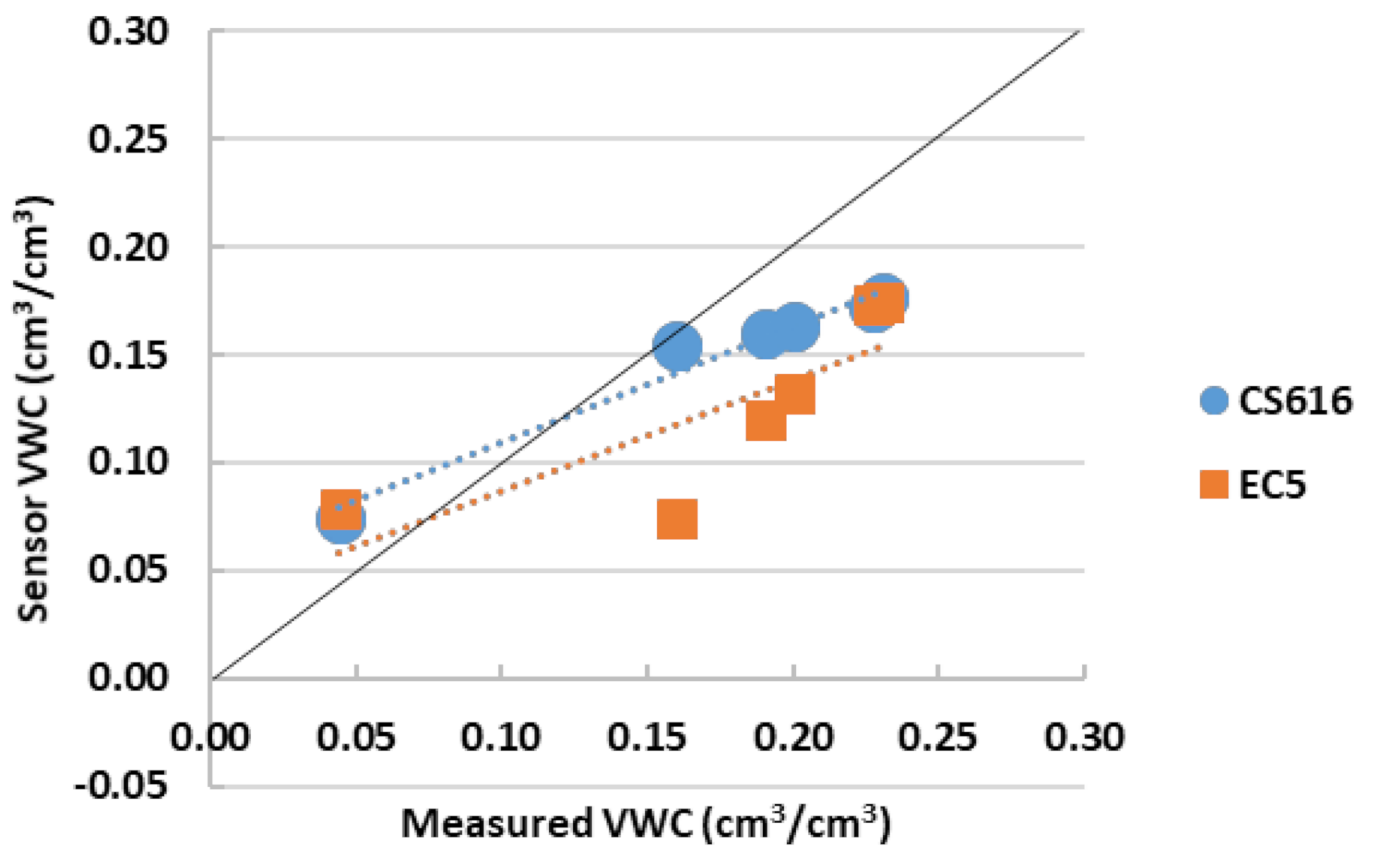

Figure 4. Comparison of CS616 and EC5 with soil sampling method for sandy clay loam.

Overall, the performance of the factory-based calibrated CS616 and EC5 sensors did not meet all the statistical criteria except the CS616 sensor in the sand. This was not unforeseen as the accuracy for CS616 and EC5 from the user manual were \pm 0.025 and $\pm 0.03 \mathrm{~cm}^{3} / \mathrm{cm}^{3}$, respectively $[18,19]$. This laboratory experiment result shows that soil moisture sensors should be calibrated for specific types of soil (site-specific conditions) to improve accuracy. This was also discussed by previous researchers $[14,15,20]$.

Based on the laboratory data, correction equations for CS616 and EC5 were developed (Table 4). $\theta_{\mathrm{vi}}$ is the value from the factory-based calibrated sensor. $\theta_{\mathrm{v}}$ is the corrected value. The logarithmic equations for EC5 for sand and loamy sand are not available, because the EC5 values at the lowest moisture content measurement were negative. Based on the previous literature, this study evaluated the performance of the sensor using the following criteria: RMSE $<0.035 \mathrm{~cm}^{3} / \mathrm{cm}^{3}$, IA $>0.8$, MBE $\pm 0.02 \mathrm{~cm}^{3} / \mathrm{cm}^{3}$, and $\mathrm{R}^{2}>0.65[14,17,21]$.

The statistical analysis result shows that all types of equations for CS616 in the sand have met the criteria. This was expected because the factory calibrated CS616 already met the criteria. Of these equations, linear and quadratic type equations of CS616 performed the best in the sand. In loamy sand, linear and quadratic type equations of CS616 have met the criteria; however, exponential and logarithmic equations did not. In sandy clay loam, all equation types have met the criteria. Linear, exponential, and quadratic equations of EC5 have met the criteria in the sand. Linear and exponential equations did not meet the criteria in loamy sand, but the quadratic equation did. In sandy clay loam, the performance of linear, exponential, and logarithmic equations was poor. Only the quadratic equation met the criteria. In general, the quadratic equations had the lowest RMSE and MBE and the highest IA and $\mathrm{R}^{2}$, which is also confirmed by other literature [21]. 
Table 4. Correction equations for CS616 and EC5 soil moisture sensors.

\begin{tabular}{|c|c|c|c|c|c|c|c|}
\hline $\begin{array}{l}\text { Soil } \\
\text { Type }\end{array}$ & Sensor & Equation Type & Equation & RMSE & IA & MBE & $\mathbf{R}^{2}$ \\
\hline \multirow{8}{*}{ Sand } & \multirow{4}{*}{ CS616 } & Linear & $\theta_{\mathrm{v}}=1.4011 * \theta_{\mathrm{vi}}-0.0213$ & 0.005 & 0.99 & 0.001 & 0.97 \\
\hline & & Exponential & $\theta_{\mathrm{v}}=0.0036 \mathrm{e}^{43.906 * \theta_{\mathrm{vi}}}$ & 0.031 & 0.84 & 0.004 & 0.88 \\
\hline & & Logarithmic & $\theta_{\mathrm{v}}=0.0577 * \ln \left(\theta_{\mathrm{vi}}\right)+0.2294$ & 0.008 & 0.97 & 0.001 & 0.92 \\
\hline & & Quadratic & $\begin{array}{c}\theta_{\mathrm{v}}=-0.5029 *\left(\theta_{\mathrm{vi}}\right)^{2}+ \\
1.4532 * \theta_{\mathrm{vi}}-0.0225\end{array}$ & 0.005 & 0.99 & 0.001 & 0.97 \\
\hline & \multirow{4}{*}{ EC5 } & Linear & $\theta_{\mathrm{v}}=0.6055 * \theta_{\mathrm{vi}}+0.0064$ & 0.003 & 0.99 & 0.001 & 0.99 \\
\hline & & Exponential & $\theta_{\mathrm{v}}=0.0083 \mathrm{e}^{19.316 * \theta_{\mathrm{vi}}}$ & 0.020 & 0.92 & 0.002 & 0.93 \\
\hline & & Logarithmic & $\mathrm{N} / \mathrm{A}$ & $\mathrm{N} / \mathrm{A}$ & N/A & $\mathrm{N} / \mathrm{A}$ & N/A \\
\hline & & Quadratic & $\begin{array}{c}\theta_{\mathrm{v}}=1.0217 *\left(\theta_{\mathrm{vi}}\right)^{2}+ \\
0.4689 * \theta_{\mathrm{vi}}+0.0083\end{array}$ & 0.002 & 0.99 & 0.001 & 0.99 \\
\hline \multirow{8}{*}{$\begin{array}{l}\text { Loamy } \\
\text { Sand }\end{array}$} & \multirow{4}{*}{ CS616 } & Linear & $\theta_{\mathrm{v}}=2.1154 * \theta_{\mathrm{vi}}-0.0465$ & 0.016 & 0.97 & -0.001 & 0.89 \\
\hline & & Exponential & $\theta_{\mathrm{v}}=0.0032 \mathrm{e}^{43.918 * \theta_{\mathrm{vi}}}$ & 0.061 & 0.78 & 0.006 & 0.85 \\
\hline & & Logarithmic & $\theta_{\mathrm{v}}=0.1157 * \ln \left(\theta_{\mathrm{vi}}\right)+0.4187$ & 0.017 & 0.56 & 0.001 & 0.88 \\
\hline & & Quadratic & $\begin{array}{c}\theta_{\mathrm{v}}=-12.181 *\left(\theta_{\mathrm{vi}}\right)^{2}+ \\
3.6501 * \theta_{\mathrm{vi}}-0.0873\end{array}$ & 0.016 & 0.97 & -0.001 & 0.89 \\
\hline & \multirow{4}{*}{ EC5 } & Linear & $\theta_{\mathrm{v}}=0.9759 * \theta_{\mathrm{vi}}-0.0283$ & 0.059 & 0.76 & -0.057 & 0.89 \\
\hline & & Exponential & $\theta_{\mathrm{v}}=0.0149 \mathrm{e}^{20.471 * \theta_{\mathrm{vi}}}$ & 0.055 & 0.81 & 0.005 & 0.85 \\
\hline & & Logarithmic & $\mathrm{N} / \mathrm{A}$ & N/A & N/A & $\mathrm{N} / \mathrm{A}$ & N/A \\
\hline & & Quadratic & $\begin{array}{c}\theta_{\mathrm{v}}=-1.7108 *\left(\theta_{\mathrm{vi}}\right)^{2}+ \\
1.1702 * \theta_{\mathrm{vi}}+0.028\end{array}$ & 0.017 & 0.97 & 0.001 & 0.90 \\
\hline \multirow{8}{*}{$\begin{array}{l}\text { Sandy } \\
\text { Clay } \\
\text { Loam }\end{array}$} & \multirow{4}{*}{ CS616 } & Linear & $\theta_{\mathrm{v}}=1.7905 * \theta_{\mathrm{vi}}-0.093$ & 0.011 & 0.99 & 0.001 & 0.97 \\
\hline & & Exponential & $\theta_{\mathrm{v}}=0.0131 \mathrm{e}^{16.505 * \theta_{\mathrm{vi}}}$ & 0.017 & 0.99 & 0.001 & 0.99 \\
\hline & & Logarithmic & $\theta_{\mathrm{v}}=0.2036 * \ln \left(\theta_{\mathrm{vi}}\right)+0.5697$ & 0.015 & 0.99 & 0.001 & 0.94 \\
\hline & & Quadratic & $\begin{array}{c}\theta_{\mathrm{v}}=13.837 *\left(\theta_{\mathrm{vi}}\right)^{2}- \\
1.5894 * \theta_{\mathrm{vi}}+0.0858\end{array}$ & 0.016 & 0.99 & 0.001 & 0.99 \\
\hline & \multirow{4}{*}{ EC5 } & Linear & $\theta_{\mathrm{v}}=1.2857 * \theta_{\mathrm{vi}}+0.0142$ & 0.037 & 0.88 & -0.001 & 0.65 \\
\hline & & Exponential & $\theta_{\mathrm{v}}=0.0439 \mathrm{e}^{10.074 * \theta_{\mathrm{vi}}}$ & 0.043 & 0.87 & -0.011 & 0.49 \\
\hline & & Logarithmic & $\theta_{\mathrm{v}}=0.1532 * \ln \left(\theta_{\mathrm{vi}}\right)+0.5019$ & 0.024 & 0.89 & -0.011 & 0.67 \\
\hline & & Quadratic & $\begin{array}{c}\theta_{\mathrm{v}}=-9.1965 *\left(\theta_{\mathrm{vi}}\right)^{2}+ \\
3.5828 * \theta_{\mathrm{vi}}-0.1146\end{array}$ & 0.034 & 0.89 & 0.020 & 0.68 \\
\hline
\end{tabular}

\subsection{Validation of Correction Equations}

The field experiment was performed to validate the correction equations. Figures $5-7$ show the comparisons of factory-based calibration of CS616 soil moisture sensors to corrected values for sand, loamy sand, and sandy clay loam, respectively. The RMSE values for factory-based calibration and after correction in sand are 0.017 and $0.006 \mathrm{~cm}^{3} / \mathrm{cm}^{3}$, respectively. This result shows the improvement of $0.011 \mathrm{~cm}^{3} / \mathrm{cm}^{3}$ with the correction equation for sand. The RMSE values for factory-based calibration and after correction in loamy sand are 0.023 and $0.021 \mathrm{~cm}^{3} / \mathrm{cm}^{3}$, respectively. This result shows that the correction equation slightly improved $\left(0.002 \mathrm{~cm}^{3} / \mathrm{cm}^{3}\right)$ in loamy sand. Another study also had RMSE values of $0.024,0.023$, and $0.044 \mathrm{~cm}^{3} / \mathrm{cm}^{3}$ in loamy sand [14]. The RMSE values for factory-based calibration and after correction in sandy clay loam are 0.039 and $0.012 \mathrm{~cm}^{3} / \mathrm{cm}^{3}$, respectively. Overall, the CS616 sensor performance was improved with the correction equations. 


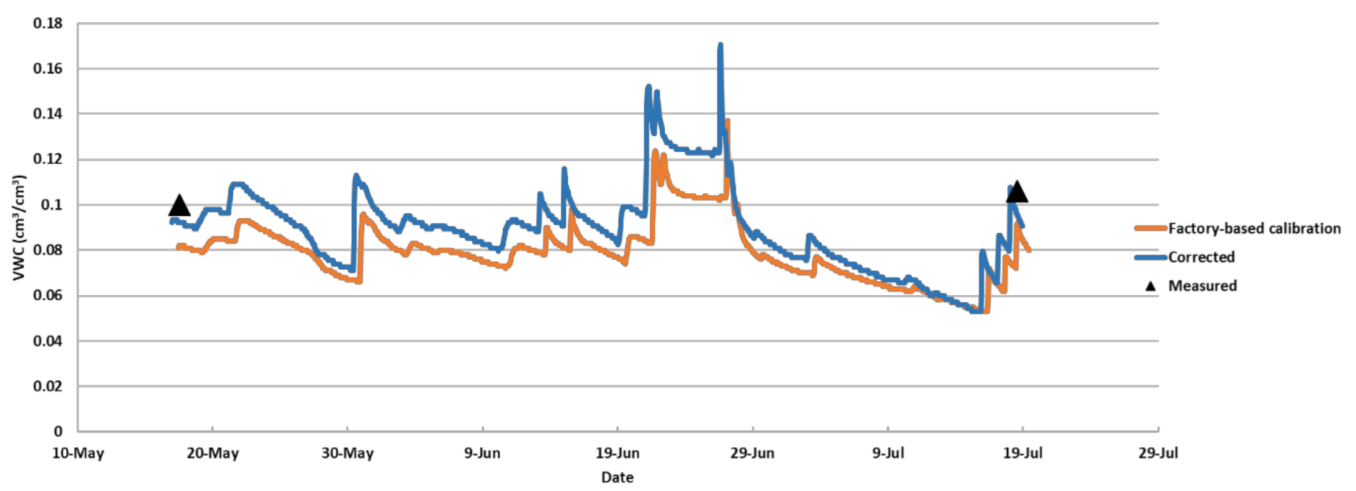

Figure 5. Comparison of factory-based calibration to corrected values for CS616 in sand.

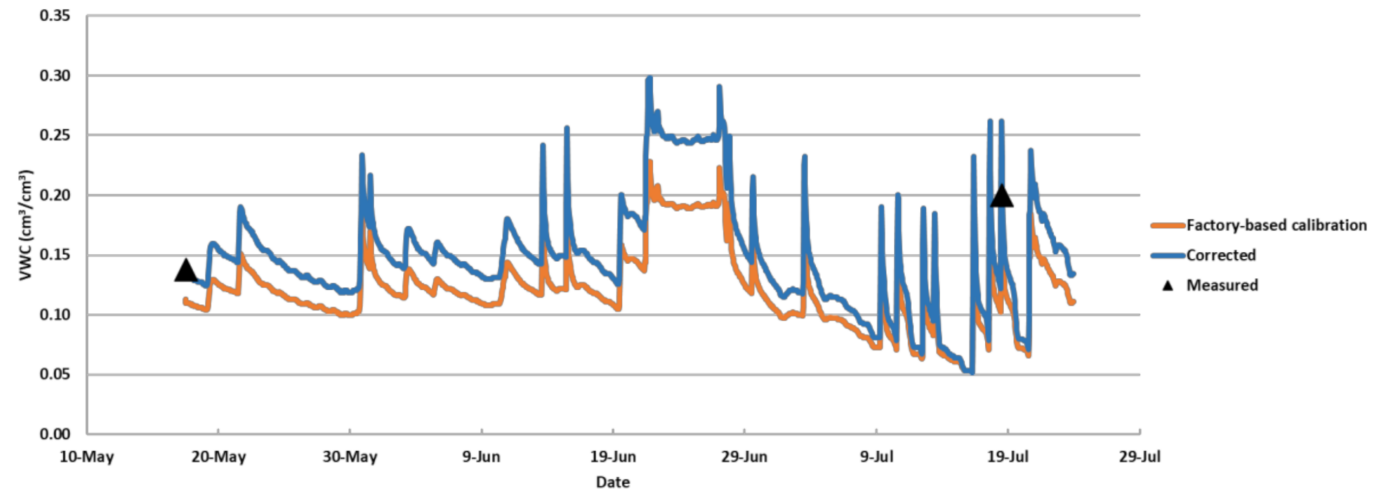

Figure 6. Comparison of factory-based calibration to corrected values for CS616 in loamy sand.

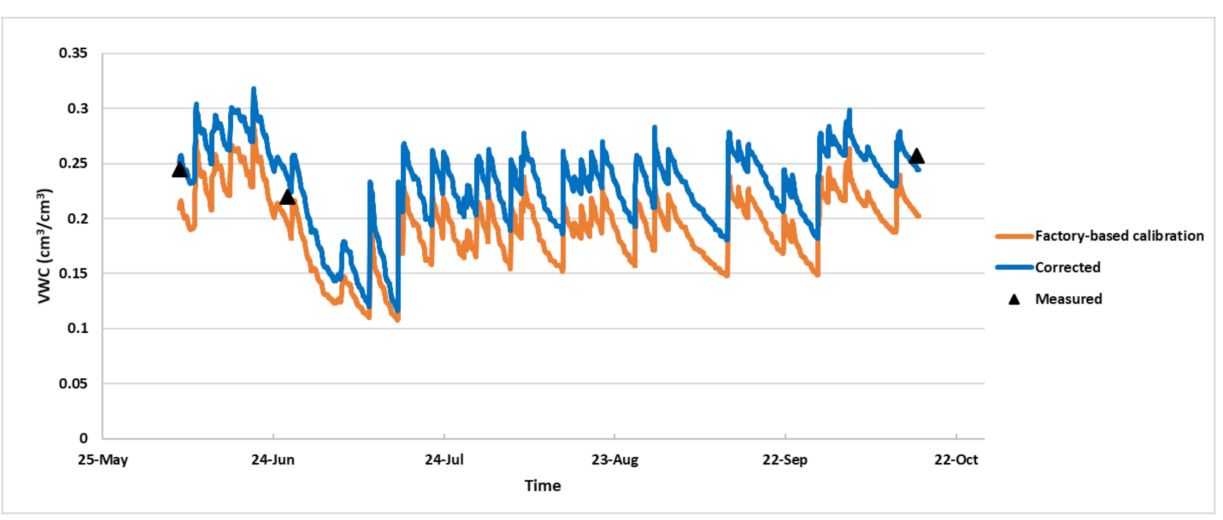

Figure 7. Comparison of factory-based calibration to corrected values for CS616 in sandy clay loam.

Figures 8-10 show the comparisons of the factory-based calibration of EC 5 soil moisture sensors to corrected values for sand, loamy sand, and sandy clay loam, respectively. The RMSE values for factory-based calibration and after correction in sand are 0.018 and $0.004 \mathrm{~cm}^{3} / \mathrm{cm}^{3}$, respectively. This result shows the improvement of $0.014 \mathrm{~cm}^{3} / \mathrm{cm}^{3}$ with the correction equation for sand. The RMSE values for factory-based calibration and after correction in loamy sand are 0.026 and $0.006 \mathrm{~cm}^{3} / \mathrm{cm}^{3}$, respectively. This result shows the improvement of $0.019 \mathrm{~cm}^{3} / \mathrm{cm}^{3}$ with the correction equation for sand. The RMSE values for factory-based calibration and after correction in sandy clay loam are 0.047 and $0.020 \mathrm{~cm}^{3} / \mathrm{cm}^{3}$, respectively. Overall, the EC5 sensor performance was much improved with the correction equations. 


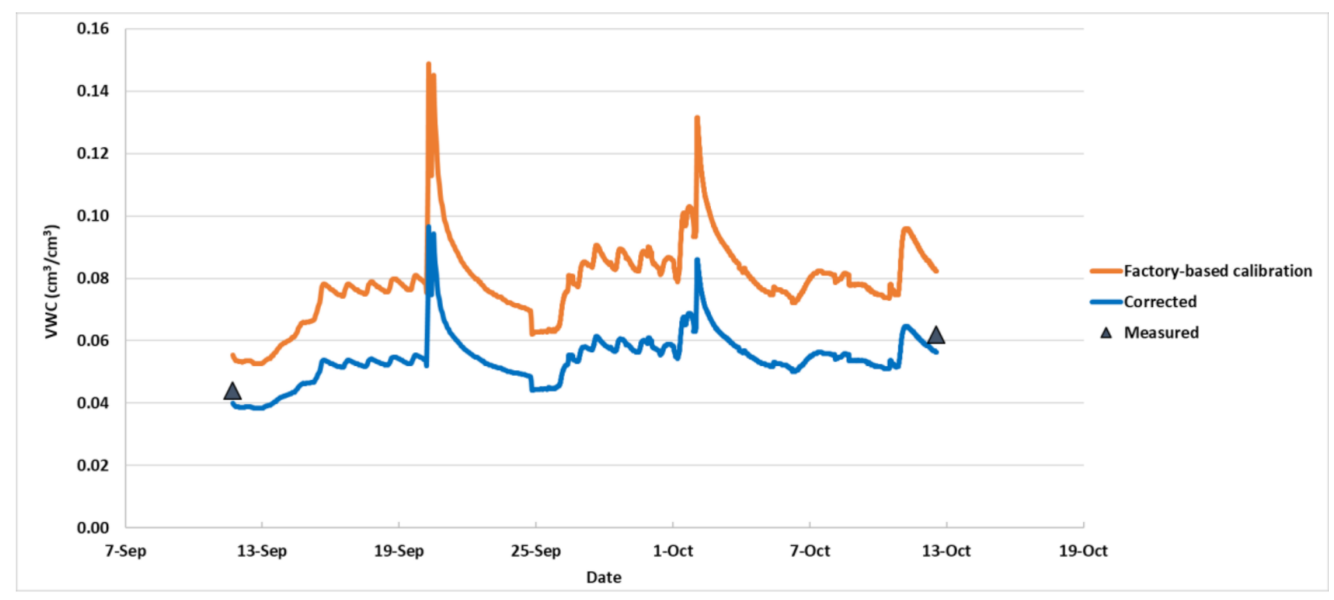

Figure 8. Comparison of factory-based calibration to corrected values for EC5 in sand.

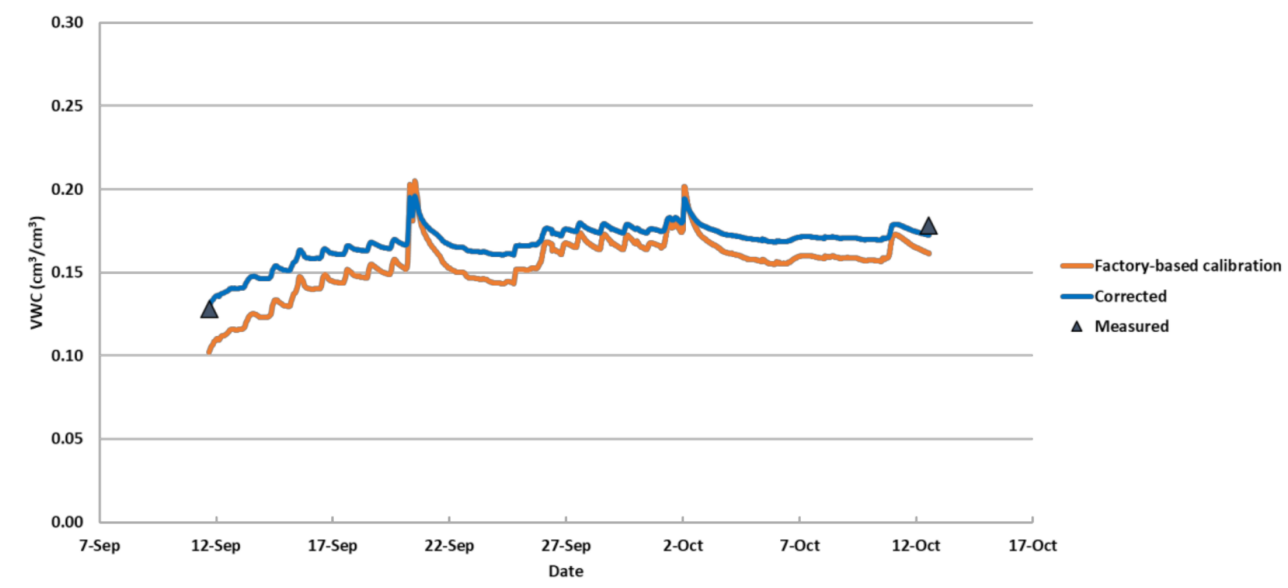

Figure 9. Comparison of factory-based calibration to corrected values for EC5 in loamy sand.

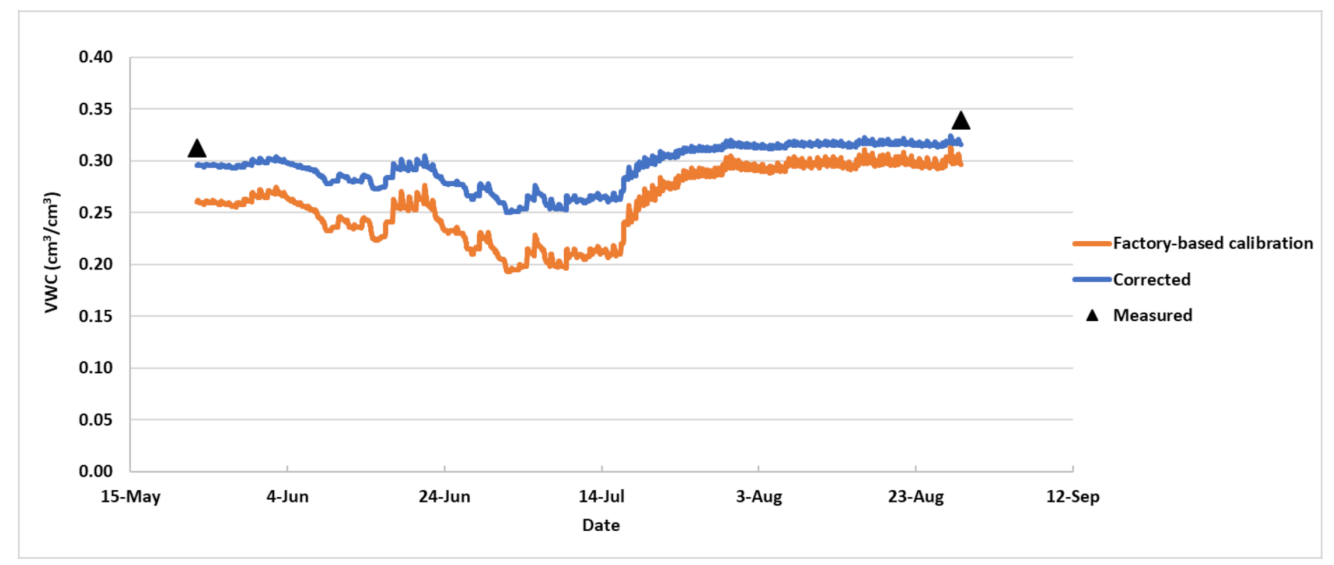

Figure 10. Comparison of factory-based calibration to corrected values for EC5 in sandy clay loam.

Besides correcting the calibration equation, the soil moisture sensor installation technique plays a significant role in determining the performance of the sensor. Because the soil moisture sensor measures only a small volume of soil surrounding the sensor, the installation should be conducted carefully. There must be good contact between the sensor and soil to avoid creating an air gap, which was also emphasized in many previous studies [22-27]. Other literature also discussed that factors, including soil temperature and salinity, could impact the sensor measurement $[11,28]$. Soil temperature fluctuations are minimized as the soil depth increases; however, an investigation under field conditions is needed in the future study. 


\section{Conclusions}

This study evaluated the performance of CS616 and EC5 soil moisture sensors through laboratory and field experiments. The performance of the factory-based calibrated CS616 and EC5 did not meet the statistical criteria except the CS616 for sand. Therefore, sensor calibration of CS616 and EC5 soil moisture sensors for each soil type is recommended. The correction calibration equations for CS616 and EC5 were developed by the laboratory experiment. Sensor demonstration from the field experiment confirmed that the correction equations improved the accuracy of the CS616 and EC5 sensor performance.

Author Contributions: Conceptualization, methodology and investigation, Y.D., S.M., and L.K.; Formal analysis, Y.D.; Writing —original draft preparation, Y.D.; Visualization, Y.D.; Writing—review and editing, Y.D. and S.M. All authors have read and agreed to the published version of the manuscript.

Funding: This research received no external funding.

Acknowledgments: The authors thank Brenden Kelley for his help with the experiment.

Conflicts of Interest: The authors declare no conflict of interest.

\section{References}

1. Engman, E.T. Applications of microwave remote sensing of soil moisture for water resources and agriculture. Remote Sens. Environ. 1991, 35, 213-226. [CrossRef]

2. Akyildiz, I.F.; Stuntebeck, E.P. Wireless underground sensor networks: Research challenges. Ad Hoc Netw. 2006, 4, 669-686. [CrossRef]

3. Ruiz-Garcia, L.; Lunadei, L.; Barreiro, P.; Robla, J.I. A Review of Wireless Sensor Technologies and Applications in Agriculture and Food Industry: State of the Art and Current Trends. Sensors 2009, 9, 4728-4750. [CrossRef]

4. Antonucci, F.; Pallottino, F.; Costa, C.; Rimatori, V.; Giorgi, S.; Papetti, P.; Menesatti, P. Development of a Rapid Soil Water Content Detection Technique Using Active Infrared Thermal Methods for In-Field Applications. Sensors 2011, 11, 10114-10128. [CrossRef]

5. Robinson, D.A.; Jones, S.B.; Wraith, J.M.; Or, D.; Friedman, S.P. A Review of Advances in Dielectric and Electrical Conductivity Measurement in Soils Using Time Domain Reflectometry. Vadose Zone J. 2003, 2, 444-475. [CrossRef]

6. Zazueta, F.; Xin, J. Soil moisture sensors. Soil Sci. 1994, 73.

7. S.U., S.L.; Singh, D.; Baghini, M.S. A critical review of soil moisture measurement. Measurement 2014, 54, 92-105. [CrossRef]

8. Walter, G. Water Content; American Society of Agronomy-Soil Science Society of America: Madison, WI, USA, 1986.

9. Cardenas-Lailhacar, B.; Dukes, M.D. Precision of soil moisture sensor irrigation controllers under field conditions. Agric. Water Manag. 2010, 97, 666-672. [CrossRef]

10. Sakaki, T.; Limsuwat, A.; Smits, K.M.; Illangasekare, T.H. Empirical two-point $\alpha$-mixing model for calibrating the ECH2 O EC-5 soil moisture sensor in sands. Water Resour. Res. 2008, 44, 181-186. [CrossRef]

11. Kinzli, K.; Manana, N.; Oad, R. Comparison of Laboratory and Field Calibration of a Soil-Moisture Capacitance Probe for Various Soils. J. Irrig. Drain. Eng. 2012, 138, 310-321. [CrossRef]

12. Stevanato, L.; Baroni, G.; Cohen, Y.; Fontana, C.L.; Gatto, S.; Lunardon, M.; Marinello, F.; Moretto, S.; Morselli, L. A Novel Cosmic-Ray Neutron Sensor for Soil Moisture Estimation over Large Areas. Agriculture 2019, 9, 202. [CrossRef]

13. Mittelbach, H.; Lehner, I.; Seneviratne, S.I. Comparison of four soil moisture sensor types under field conditions in Switzerland. J. Hydrol. 2012, 39-49. [CrossRef]

14. Varble, J.; Chávez, J.L. Performance evaluation and calibration of soil water content and potential sensors for agricultural soils in eastern Colorado. Agric. Water Manag. 2011, 101, 93-106. [CrossRef]

15. Da Silva, T.J.A.; Bonfim-Silva, E.M.; Pacheco, A.B.; Duarte, T.F.; Sousa, H.H.D.F.; José, J.V. Evaluation of Various Soil Moisture Sensors in Four Different Soil Types. Appl. Eng. Agric. 2018, 34, 963-971. [CrossRef]

16. Willmott, C.J. On the validation of models. Phys. Geogr. 1981, 2, 184-194. [CrossRef] 
17. Hignett, C.; Evett, S. Direct and surrogate measures of soil water content. In Field Estimation of Soil Water Content; International Atomic Energy Agency (IAEA): Vienna, Austria, 2008; pp. 1-21.

18. Campbell Scientific CS616. Available online: https://www.campbellsci.com/cs616-reflectometer (accessed on 11 July 2020).

19. METER Group ECH2O EC-5. Available online: https://www.metergroup.com/environment/products/ec-5soil-moisture-sensor/ (accessed on 11 July 2020).

20. Kargas, G.; Soulis, K.X. Performance Analysis and Calibration of a New Low-Cost Capacitance Soil Moisture Sensor. J. Irrig. Drain. Eng. 2012, 138, 632-641. [CrossRef]

21. Chen, Y.; Marek, G.W.; Marek, T.H.; Heflin, K.R.; Porter, D.O.; Moorhead, J.E.; Brauer, D. Soil Water Sensor Performance and Corrections with Multiple Installation Orientations and Depths under Three Agricultural Irrigation Treatments. Sensors 2019, 19, 2872. [CrossRef]

22. Walker, J.; Willgoose, G.R.; Kalma, J.D. In situ measurement of soil moisture: a comparison of techniques. J. Hydrol. 2004, 293, 85-99. [CrossRef]

23. Hanson, B.R. Field Estimation of Soil Water Content: A Practical Guide to Methods, Instrumentation and Sensor Technology. Vadose Zone J. 2009, 8, 628. [CrossRef]

24. Hillel, D. Environmental Soil Physics: Fundamentals, Applications, and Environmental Considerations. In Environmental Soil Physics; Academic Press: San Diego, CA, USA, 1998.

25. Bell, J.; Dean, T.; Hodnett, M. Soil moisture measurement by an improved capacitance technique, part II. Field techniques, evaluation and calibration. J. Hydrol. 1987, 93, 79-90. [CrossRef]

26. Rothe, A.; Kreutzer, K.; Matthies, D.; Hess, U.; Ansorge, B.; Weis, W. Changes in soil structure caused by the installation of time domain reflectometry probes and their influence on the measurement of soil moisture. Water Resour. Res. 1997, 33, 1585-1593. [CrossRef]

27. Dong, Y.; Miller, S.; Kelley, L. Improving Irrigation Water Use Efficiency: Using Soil Moisture Sensors. Available online: https://www.egr.msu.edu/bae/water/irrigation/sites/default/files/content/E3445_ ImprovingIrrigationWaterUse.pdf (accessed on 11 July 2020).

28. Nagahage, E.A.A.D.; Nagahage, I.; Fujino, T. Calibration and Validation of a Low-Cost Capacitive Moisture Sensor to Integrate the Automated Soil Moisture Monitoring System. Agriculture 2019, 9, 141. [CrossRef]

Publisher's Note: MDPI stays neutral with regard to jurisdictional claims in published maps and institutional affiliations.

(C) 2020 by the authors. Licensee MDPI, Basel, Switzerland. This article is an open access article distributed under the terms and conditions of the Creative Commons Attribution (CC BY) license (http://creativecommons.org/licenses/by/4.0/). 